\title{
Experience of Formation of the Scientific Research Environment At Russian Universities
}

\author{
Ludmila N. Zanfir
}

\begin{abstract}
The article analyzes the role of all disciplines of the curriculum during the preparation of a modern student. The development of the organization of research work with students is shown on the example of the leading engineering university of Russia of the Tyumen Industrial University. The experience of creating real conditions for the active inclusion of students in research at the Mordovian State Pedagogical Institute named after M.E. Evseeva.

The work summarizes the many years of experience in organizing scientific work with students in conducting sociological research in a technical university. The features of the methodology of working with bachelors at all stages of the preparation and conduct of a sociological study are examined, a description of the workshops is given. The results of surveys on youth issues conducted at the Surgut Institute of Oil and Gas are presented, the basis of which is a concept developed by $0 . O$. Gorshkova.
\end{abstract}

Keywords : research work with students, humanitarian disciplines, activity approach, future engineer.

\section{INTRODUCTION}

Tyumen Industrial University is positioned as a research university, which, in addition to providing educational services, requires the development of research skills. The important role of scientific research in higher education is confirmed by government documents adopted in recent years. The document "Strategy for the innovative development of the Russian Federation for the period until 2020" outlines the goals facing higher education institutions: the involvement of university scientists and students in the innovation process to improve the quality of specialist training; increasing the role of universities in the country's economy as regional development centers in the scientific, technical and educational fields; training and retraining of personnel for scientific and technical entrepreneurship and the management of scientific, technical and innovative projects, the creation of a single information space for the innovative activities of higher education, the conditions for coordination and integration of higher education institutions with industrial enterprises through the formation on their basis of educational and scientific and innovative complexes and federal research universities [1].

The following tasks of research work with students are defined at the Tyumen Industrial University : identification of the most gifted and advanced students with a pronounced motivation for scientific activity; favorable

Revised Manuscript Received on October 15, 2019.

* Correspondence Author

Ludmila N. Zanfir, Tyumen Industrial University, Volodarsky Str, 38, Tyumen, Russia. conditions for the development and implementation of various forms of scientific creativity of youth, based on the domestic and foreign experience and the results of scientific and methodological developments; assistance in the comprehensive development of the student's personality, the formation of his objective self-esteem, the acquisition of independent work skills and work in creative teams, mastery of the research methodology; ensuring the participation of students in conducting applied, fundamental, search, methodological and pedagogical scientific research in priority areas in various fields of science and technology; the integration of scientific and practical potentials of teachers and students, aimed at solving scientific and technical problems in various fields of science and technology.

All subjects of the curriculum are involved in preparing students for scientific research. In the process of studying subjects of the socio-humanitarian cycle, a personal worldview is formed, an understanding of the engineer's social responsibility for the development and implementation of new technical projects. The foundations of the theory and methodology of knowledge are laid, students gain knowledge on the history of the development of science and technology. Mathematical preparation allows you to make calculations, without which the implementation of any technical project is unthinkable. Natural science disciplines provide basic knowledge about the essence of processes occurring in nature, about the general laws of functioning of systems, about the mechanisms and principles on the basis of which technology works. The disciplines of the general professional cycle, in turn, form a system of knowledge about the technique and technologies of the industry, innovative projects and development prospects, acquaints with calculation methods for practical application in future professional activities. The assimilation of a wide variety of knowledge broadens the horizons of scientists and inventors and creates the prerequisites for the creative solution of tasks at the junctions of different sciences. This is important because scientific and technological breakthroughs are increasingly taking place in this direction.

Since the university is positioned as a research university, humanities must make their contribution, including to the organization of research work in their areas of educational activity. Humanitarian disciplines, by virtue of their specificity, help the development of innovative thinking. To generate new ideas, in addition to logical thinking engineer needs to possess such qualities, as a developed imagination, a tendency to associative thinking, scientific and technical intuition. The development of imaginative thinking is necessary, since ideas and hypotheses arise first in visual-sensory images, and then 
are embodied in formulas and real objects.

In a modern society of risks, when a person is placed in conditions that dictate the need to constantly make decisions in unusual situations, the humanitarian style of thinking has certain advantages. A modern person often finds himself in situations that, based on a synergetic paradigm, can be modeled as a "bifurcation point", when it is already impossible to live and act, and it is necessary to choose the right strategy from a number of possible options for further development. Often amid missing information. Thinking formed in the process of studying natural-scientific and technical disciplines works on the principle of determinism: cause-effect. Most of the tasks in these areas of knowledge are structured as follows: given: ... using the law (formula), find the value (plot, determine, etc.). That is, consciousness works according to a predetermined scheme. A brain trained in this way under conditions of chaos, when many factors act, and cause-effect relationships are difficult to trace, is at an impasse. The principle of humanitarian thinking is different: there are always a number of alternative options, and the subject of cognition must find the best. Organic synthesis of both types of thinking gives the necessary positive result.

\section{METHODOLOGY}

In order to study the attitude of students of technical universities to the humanities at the Russian University of Chemical Technology DI. Mendeleev's survey was conducted, in which 100 students of 2-5 courses from different faculties participated. When asked whether humanitarian subjects are needed for students of technical specialties, $77 \%$ of the respondents gave affirmative answers. Among the most useful disciplines were noted psychology (65\%), Russian language and culture of speech (61\%), history (52\%), sociology (34\%), philosophy 30\%. Most respondents believe that humanitarian courses are needed for technical students for overall development (73\%) [2, p. 360-361]. Surveys of graduates of the Surgut Institute of Oil and Gas, conducted in 2015, showed similar results. The questionnaire included questions about how seriously students took humanitarian subjects: $46 \%$ of respondents said that they were serious; almost $40 \%$ of respondents said that they were not very responsible, and about half of them regretted that a lot of useful things had been lost, the rest admitted that they considered humanitarian items unnecessary. On the whole, towards senior courses, a change in the attitude towards humanitarian subjects towards a positive one is observed [3, p. 18-19].

The topic of preparing students for research activities was not raised by chance, since life shows that in a number of cases engineers experience significant difficulties in this regard when solving production problems. The analysis of this problem is devoted to the work of V.I. Zagvyazinsky, V.I. Kondrukh, A.M. Novikova, G.M. Ovchinnikov and other authors. As O. Gorshkova notes, "The reasons for this situation lie in the existing practice of training future engineers at universities, which does not provide them with the necessary experience in research activities, and does not contribute to the development of research competencies" [4, p.25].

To create an environment of intellectual creativity in the university, it is necessary to use different methods: to inform students about the achievements of students of past years in terms of research, participation in competitions and conferences, scientific publications. Give examples of the impact of active research activities of the most successful graduates on the growth of their professional career. And here it is appropriate to recall and use the experience of Soviet higher education. For example, in technical universities, patent science was studied as a compulsory subject. The main attention was paid to the information support of inventions, the preparation of application materials and the patenting procedure. Obtaining copyright certificate was considered as a high indicator of the work of a specialist and team. Advocacy of heuristic methods in science and industry was carried out by public organizations through a system of continuing education courses, which helped to stimulate the inventive activity of engineering and technical workers. At present, the formation of an environment of intellectual creativity is taking place at a new qualitative level: large amounts of money are being invested in creating a system of new forms, such as an incubator, technopark, and technopolis. The development of invention and scientific and technical creativity is considered as one of the aspects of the innovation processes of Russian higher education.

From the point of view of the acmeological approach, an important aspect of research is personality development. This approach takes into account the influence of the family, the teaching staff, and the professional group, traces the mechanisms of influence on the personality of various factors. The ability to research activity is considered from this point of view as an indicator of specialist maturity. S.V. Skifsky considers readiness for innovative activity "as a certain formation of a person's personal resource, ensuring the freedom of his intellectual self-realization in a changing social reality" $[5$, p. 5]. The author focuses on the formation of an environment of intellectual creativity at the university. It is much more difficult for a loner to realize his creative potential. The process of managing innovative activities should be aimed at creating the most favorable conditions for creative activity. A set of measures is needed to ensure the involvement of students in scientific activity, their further support and encouragement. The attractive environment of intellectual creativity S.V. Scythian defines it as "the conditions for involving students in the process of scientific research ... The formation of an environment of intellectual creativity should increase the" synergy "of the university community, bring a positive effect of maximum cooperation, when each member of the group and the institution as a whole benefit from the success of its other members " $[5, p$. 15-16].

The student scientific community should have an attractive goal, attracting new participants to the implementation of the project. Such goals are determined by important (system-forming) events. As an example, one of the most resonant events in the field of innovative automotive industry is the "Formula Student" project, where teams of students from leading technical universities compete in the creation of new models of sports racing cars. Every year international competitions are organized, during which, in addition to racing, tests are 
carried out for profitability, environmental friendliness, design, and safety. It is an honor to be among the project participants for both the team and the university. Now in competitions, which are regarded as a kind of engineering world championship among students, more than 500 universities from 40 countries from around the world are participating, and their number is increasing. In Russia, there are about 10 teams, one of which is the team of the Tyumen State Oil and Gas University " Formula Neftegaz". The olides, assembled by the hands of Tyumen students, were tested in Italy, Hungary, Moscow, and China. The team should not only design, build and test the car, but also develop a business plan for small-scale production, conduct a public relations campaign. Therefore, young designers collaborate with students of the Institute of Management and Business - future economists and specialists in the field of PR. Participation in the project develops not only the ability to solve complex technical problems, but also makes it possible to show organizational skills in terms of coordinating the work of the group, public relations, organizing business, international communications, etc.

Experience in creating real conditions for the active inclusion of students in research is available in many universities in the country, including in the regions. At the Mordovian State Pedagogical Institute. M.E. Evseeva functions of coordination, attraction and support of young people in research activities are performed by the Council of Young Scientists and the student scientific society. These structures are engaged in the organization of fundamental and applied research in priority areas, the selection and attraction of talented youth in the field of science and education. SSS unites more than 200 student scientific communities (research groups, circles, interest clubs, centers, laboratories), in the research and design work of which more than 1700 students are involved. Financial and logistical support creates favorable conditions for young scientists, graduate students, applicants, and students to conduct research. Internships are also financed on the basis of leading scientific and educational institutions, business trips to creative contests and scientific conferences $[6, \mathrm{p}$. 55-56].

The basis for the organization of the process of preparing students for research activities at the Surgut Institute of Oil and Gas is a concept developed by Dr. O. O. Gorshkova. [7, p.21]. The concept is based on advanced ideas for the modernization of Russian and foreign higher education. The model of preparing students for research activities includes the following interrelated sections (blocks): “ creation of an innovative educational environment that ensures the implementation of students' research activities; $n$ elenapravlennoe formation of readiness for research activities as a mandatory component of the engineer training in accordance with the federal state educational standards; the formation of students' motivation for research activities; establishing partnerships between the teacher and students based on the adoption of common goals; the existence of intersubject integration, the inclusion in vocational training of special courses, special workshops ; selection and rational combination of traditional and interactive forms and methods of mastering the content of the curriculum, the use of information technology; the use of

integrated research projects, end-to-end research tasks in the implementation of term papers and final qualification work" [7, p. 20 - 21].

In the framework of the activity approach, the author identifies four groups of components necessary for preparing for research activities: cognitive, motivational, orientational, operational. The cognitive component is a set of knowledge necessary for an engineer to solve research problems in his professional activity. The motivational component is the factors that prompt a person to research, give it meaning. An indicative component is the ability to determine the current topic of research and finding the best ways to solve it in the existing conditions. The operational, or technological cue component includes a set of abilities, skills, techniques that are owned by the subject, and is ready to apply for professional research tasks.

The main requirement for enhancing students' research activities was the modeling of conditions close to production. In the process of testing the system (educational program), attention was focused on creating an atmosphere of cooperation and co-creation of teachers and students. The student was given the role of an active subject of his own cognitive and research activities, and the teachers took the position of assistants, consultants. The degree of freedom in the search for ways to solve research problems increased gradually: from a detailed explanation with specific examples at the first stage of training to general control of the final result. During the implementation of the author's specialized courses "Fundamentals of the methodology of scientific research", "Fundamentals of the research activity of an engineer", "Professional self-determination", students solved research problems of various types and levels of complexity, performed creative tasks, learned to generate ideas, fantasize, model, etc. A special role in modeling situations was given to gaming technologies. For this, educational (cognitive, training), developing and communicative games were used. The ratio of time allotted to classroom and independent work was approximately $60 \%$ to $40 \%$ [4, p.27].

\section{RESULTS}

In an experiment to study the impact of introducing an author's model in the educational process, 120 SING students (group B) and 50 students of SurGU - control group "A" took part. In group B, at all stages, design and problematic teaching methods were actively applied, special workshops, business games were held, interactive and interactive forms were used. Training in group "A" was carried out in the framework of the traditional system. At the end of each academic year, control tests were conducted to compare the results and determine the effectiveness of the factors of the new system. If at the initial stage both groups showed the same indicators (at the input control, more than $90 \%$ had a weak idea of the structure and methods of conducting scientific research), then at the end of the experiment the results for all components were significantly different: in the experimental groups they were an order of magnitude higher [8, p.228]. 
Table 1:Summary of Integrated Research Readiness Assessment

\begin{tabular}{|l|c|c|c|c|}
\hline Integral Research & \multicolumn{2}{|c|}{ SING } & \multicolumn{2}{c|}{$\begin{array}{c}\text { Surgut State } \\
\text { University }\end{array}$} \\
\hline & Course & Course & Course & Course \\
& 1 & 4 & 1 & 4 \\
$\%$ & $\%$ & $\%$ & $\%$ \\
\hline tall & 0 & 20 & 0 & 2 \\
\hline above the average & 0 & 31 & 0 & 4 \\
\hline average & 0 & 40 & 0 & 31 \\
\hline below the average & 1 & 4 & 1 & 36 \\
\hline low & 4 & 4 & 5 & 20 \\
\hline not formed ( zero) & 95 & 1 & 94 & 7 \\
\hline X 2 & \multicolumn{2}{|c|}{172,8} & \multicolumn{2}{c|}{79} \\
\hline
\end{tabular}

The data given in the table confirm the effectiveness of the implemented model.

The need for the formation of an educational environment is confirmed by a number of experiments and the results of opinion polls. So, in a monographic study conducted by S.V. Scythian on the basis of the Tyumen State Oil and Gas University in order to identify factors of intensification of intellectual creativity, students and graduate students from the fields of Applied Geology, Oil and Gas Business, Equipment and Units of Oil and Gas Production and others participated. Only 240 people. The sample structure was 3 groups:

Group "A" (80 people) - graduate students and students who were not involved in inventions; the curriculum does not contain targeted courses related to technical creativity and patent activity.

Group "B" (80 people) - graduate students and students with an idea of invention, the training program includes the courses "Fundamentals of Technical Creativity" or "Protection of Intellectual Property".

Group "C" (80 people) - and graduate students and students who have completed the program "Technical Creativity: Foundation, Process, Result".

In the course of the study, the following methods were used to collect information: content analysis of documents, questionnaires, non-standardized observation, conversation [9]. A content analysis of state educational standards in the oil and gas sector showed that the component of social and humanitarian disciplines of worldview content averages 17\% of the total academic load. The presence of disciplines aimed at developing intellectual creativity skills is a rare exception.

\section{CONCLUSION}

The results of the behavior of S.V. Scythian questionnaires showed that the majority of respondents highly value the role of scientific and engineering creativity. As a reason for turning to this type of activity, $30 \%$ of all respondents indicated "the opportunity to experience the joy of creativity", 20\% - "prestige and success", 20\% - "personal professional growth", 15\% - "the pursuit of the public good", $13 \%$ - "personal material benefit", $8 \%$ - "management requirements". On the issue of responsibility for the results of introducing innovations, unanimity was also shown: $85 \%$ of respondents from all groups assign it to the authors and executors of projects, experts, and to the government. But in a number of positions the opinions of the respondents of groups " $\mathrm{A}$ ", "B" and " $\mathrm{C}$ " diverged. The high importance of intellectual creativity for themselves is personally noted by $55 \%$ and $68 \%$ of respondents from groups "B" and "C", respectively, and only $35 \%$ from group "A".

The state of the humanitarian component of education leaves much to be desired: a sufficient level of knowledge about the essence of the theory of sustainable development of society was demonstrated by $8 \%$ of group "A", $10 \%$ of group "B", $30 \%$ of group "C". $83 \%$ of respondents of groups "A" and "B", $90 \%$ of group "C" were able to substantiate the consequences of scientific and technological progress and model one or two strategies for the development of civilization; up to six strategies $-45 \%$ of the "C" group [5, p. 29-32]. The conclusion is obvious: in groups where special courses were purposefully read, the level of the scientific worldview and the motivation for research and engineering activities are an order of magnitude higher.

\section{REFERENCES}

1. Strategy of innovative development of the Russian Federation for the period until 2020 // Access mode: http://minsvyaz.ru/common/upload/227-pril.pdf

2. Ryazantseva, A.A. The value of humanitarian training in technical universities through the eyes of students / A.A. Ryazantseva // Modern educational technologies and their use in the system of humanitarian training of engineers. - M.: MSTU. N.E. Baumann, 2010. - pp. $360-362$.

3. Zanfir, L.N. The influence of the quality of the study of humanitarian subjects on the preparation of final qualifying work / L.N. Zanfir // Global Scientific Potential. Scientific - practical journal. - 2015. - No. 5 (50). pp. 17-19.

4. Gorshkova, O.O. An active approach to building a system for preparing future engineers for research / O.O. Gorshkova // Fundamental Research . - 2012. - No. 3-1 . - pp. 25-28.

5. Scythian, S.V. Sociocultural factors of designing an attractive environment of intellectual creativity at a university: dissertation abstract Doctor of Sociological Sciences / S.V. Scythian. - Tyumen, Tsogu, 2007. - 44 p.

6. Shukshina, T.I., Zamkin P.V. The development of research activities in a pedagogical university / T.I. Shukshina, P.V. Zamkin // Higher education in Russia. - 2012. - No. 5 . - pp. 54-62.

7. Gorshkova, O.O. The concept of preparing engineering students for research activities / O.O. Gorshkova // Higher education today . - 2015. № - 8 . - pp. $18-21$.

8. Gorshkova, O.O. Preparation of future engineers for research activities Gorshkova. - Tyumen: Tsogu , 2013.-272 p.

9. Zanfir , L.N. The use of sociological methods in the preparation of students' research work: a training manual / L.N. Zanfir . - Tyumen: Tsogu, 2014 . - $96 \mathrm{p}$.

10. Markova, SM, Zanfir , LN, Vaganova , OI, Smirnova, ZV, \& Tsyplakova , SA (2019). Department of educational process in conditions of implementation of interactive training of future engineers. Amazonia Investiga , 8 (18), 450-460.

11. Sedykh, EP, Zanfir , LN, Vaganova , OI, Smirnova , ZV, \& Bulayeva , MN (2019). Use of training technology in the preparation of students of engineering specialties. Amazonia Investiga , 8 (18), 461-470. 